\title{
Linguistic Identity of the Members of the British Lingvoculture in the Aspect of Modern Socio-political Situation
}

\author{
L.M. Bolsunovkaya ${ }^{1, a}$, I.A. Kuprieva ${ }^{2}$, and S.B. Smirnova ${ }^{3}$ \\ ${ }^{1}$ Belgorod State National Research University, 308001 Pobedy st., 85, Belgorod, Russia \\ ${ }^{2}$ Tomsk Polytechnic University, 634050 Lenin Avenue, 30, Tomsk, Russia \\ ${ }^{3}$ Belgorod State National Research University, 308001 Pobedy st., 85, Belgorod, Russia
}

\begin{abstract}
The paper deals with the identity problem of the members of the British lingvocultural society in the course of modern socio-political situation in the UK. The modern historical period is recognized to be one of the most difficult in the modern world of globalization. Current local conflicts in the Middle East make people move to Western Europe to seek for a better life. Therefore, a flow of refugees comes to the UK, bringing not only their language, but also their traditions and culture in general. It initiates blending processes that causes changes in culture, as well as in a language. As the language serves as the means of communication as well as the human experience storage, that helps to save the cultural specialities. These changes can be observed in the language by means of studying the factual material, and we consider the corresponding web-resources and chats that contain linguistic observations of different aspects of the immigration problem. Thus, general conclusions are made on the study of the linguistic material, especially the online resources of the relevant mass media.
\end{abstract}

\section{Introduction}

The modern world becomes more and more globalized through the united communicative space of the Internet and the united economic area. Though the problems of energetic resources and gaining more political weight strengthen the problem of radicalism, and terrorism forces the world leaders to move against the terrorist groups and start different local conflicts. Thus, many people try to flee from these threats and thus become refugees who seek a better future in Europe. This model of multiculturalism and universal tolerance to large ethnic and religious communities that are poorly adapted to the Western cultural canon is not able to integrate fully into the British community and thus is being replaced by the new far-right mood that opposes the Muslim communities in the country. This mood is justified by the fact that the latter are other carriers, who are incompatible with Western cultural norms and traditions, which are a threat to the normal existence and development of the British nation. In this aspect the aim of the present article is to undertake a study of attitudes of the British lingvoculture members and set the change of values, characteristic of the modern young man.

The research work consists in providing an analytical review of linguistic and non-linguistic literature on the basis of systematization of information in the field of foreign research on ethno-cultural identity. The study of interethnic relations and adaptation to the cultural environment will be carried out. A number of issues of identity, influence of the ethno-cultural and sociopolitical situation on the language environment will be considered. This review will provide objective data on the achievements of modern science in the field of interethnic relations and ethno-social processes and their fixation in a language, which will make it possible to expand the research capacity in the field of the interethnic and inter-confessional situation in the social environment and present the prospects of the upcoming study. Along with the description of the theoretical foundations of the study, primary research thesaurus will be gained, verified and processed. Units of the thesaurus researched will be reflected in the relevant database, which will store information about the semantic shifts in the vocabulary in the synchronic aspect. In the future, such a database would be relevant for the comparative analysis of the description of the language changes. Data of the obtained database and information on the main factors, influencing the changes in a language, will form the basis of the immersed empirical research program, which will also reflect relevant techniques for monitoring the language situation in selected aspects, as well as study the language changes together with the development of the current socio-political situation in the world. This program will be a comprehensive study of psycholinguistic, sociological and ethno-cultural

\footnotetext{
a Corresponding author: bolsunovskl@tpu.ru
} 
aspects of linguistic identity and contribute to the improvement of the conceptual and methodological basis of the study through a multi-level system of demographic, ethnic, cultural and political processes in the system of international relations. Consideration of the linguistic and non-linguistic factors obtained will allow conditionally presenting a mental structure that will serve as a basis for creating a deep model of linguistic invariants and variants.

\section{Materials and methods}

The aims of the research undertaken limit the methodological base, especially in using traditional linguistic methods. The use of the natural scientific methods of analysis and work with information in the described study is an innovative approach in achieving this goal and allows us to expand the methodological basis of linguistic research with new tools. The widely used methods combine traditional and modern linguistic ones. The first is the definitional analysis that allows determining the system value of a lexeme, its significative, denotative and, if available, connotative aspects of the meaning). The next is the contextual analysis that let us define the functional value of a lexeme. The modern methods are lingvocognitive simulation and the conceptual analysis, which allow graphical modelling of the studied mental structure and verifying the research corpus. Lingvo-axiological tools let us set the evaluative component. Lingvo-synergetic tools provide an opportunity to identify areas of modification vocabulary values. Besides, there are reinterpreted natural science methods. They are the method of classification, synthesis, and the method of clustering, which allows looking at the problem from a completely new angle, providing flexibility and ability to obtain the research data regarding the prognostic verbalization process of self-identification of British young people in virtual space. These sets of methods give the opportunity to solve the corresponding tasks. The knowledge and regulations, developed in modern linguistics to achieve this goal, are planned by solving a number of tasks. The first is to present the theoretical bases of research funds, linguistic identity of the British young people in virtual space. That means to carry out a systematic analysis of the scientific literature in the fields of history, sociology to describe periodization studies, extra-identifying factors influencing the value system of youth protection, the definition of fundamental importance and the key parameters of British youth identity in the value aspect in the modern world. The next is to carry out a study of attitudes of the British and set the change of values, characteristic of the modern young man. The third is to conduct relations periodization of British society to a multicultural model and to identify markers of positive and negative mood (modus) and their verbalization in the discursive space. The fourth is to provide an analysis of existing Internet resources, especially popular among British youth, to reveal the similarities and differences of these sites, the target audience. The fifth is to carry out a continuous sample of lexical units, recurrently used by the British youth to express attitude to the ongoing situation in the world and the expression of identity in the virtual space (in the Public material, blogs, video sharing and comments to them). The sixth is to carry out the primary analysis of the vocabulary obtained under microcontext and to create a primary database for the subsequent formation of a research body. The last is to carry out component, morphological and contextual analysis of neologisms and nonce words and to establish their frequency, exercise axiological tagging tokens in the context interpretation and on the basis of grouping of the previously tagged lexemes. The material corpus of the study is of a great variety. The Internet with the great number of its accessible and both reliable resources gives the opportunity to study mass of the online versions of traditional mass-media as well as different You Tube sources and chats, and thus to reveal the ongoing changes.

\section{Results and discussion}

The present article deals with the study and description of linguistic identity in the linguistic culture in terms of contemporary socio-political situation in the world, given the impact of interethnic and interconfessional contacts. The object of study, that is the language material, collected while studying the corpus of the relevant web-resources and chats given the synchronic aspect, will be investigated for "resistance" of its semantics to the effects of language and cultural characteristics of migrants and refugees. In addition, given the cognitive-oriented nature of the study undertaken will be taken into account, and furtherly predicted national and regional characteristics of behavioural stereotypes (mentality) of the UK, influencing the style of everyday life, the positive and negative perceptions of global migration processes, important social and economic period, the reaction to the influx of refugees into their countries will be taken into account and further predicted. It is assumed that the tolerance, as well as the real attitude of a lingvoculture to the forced changes are naturally recorded in the language, namely in the semantics of language units. Accordingly, such an extension of semantics entails changes in the individual and, as a consequence, the national semantic space that will be investigated.

Modern social and political situation in the world in many aspects is a motivating start for a scientific research. Now, as never before, Europe receive migrants and refugees from all over the world, searching safety and a better life.

When studying the official data concerning the migrants inflow in diachronic aspect one can observe a great increase of the corresponding figures. These are the data presented in the Briefing "Migrants in the UK: An Overview» (http://www.migrationobservatory.ox.ac.uk/ briefings/migrants-uk-overview), published in 2015. Data for 2016 are now unavailable, caused by the current 
socio-political situation in Western Europe, we suppose. The stock of the migrant population almost doubled from 1993 to 2014 The size of the foreign-born population in the UK increased from about 3.8 million in 1993 to over 8.3 million in 2014 (see Figure 1).

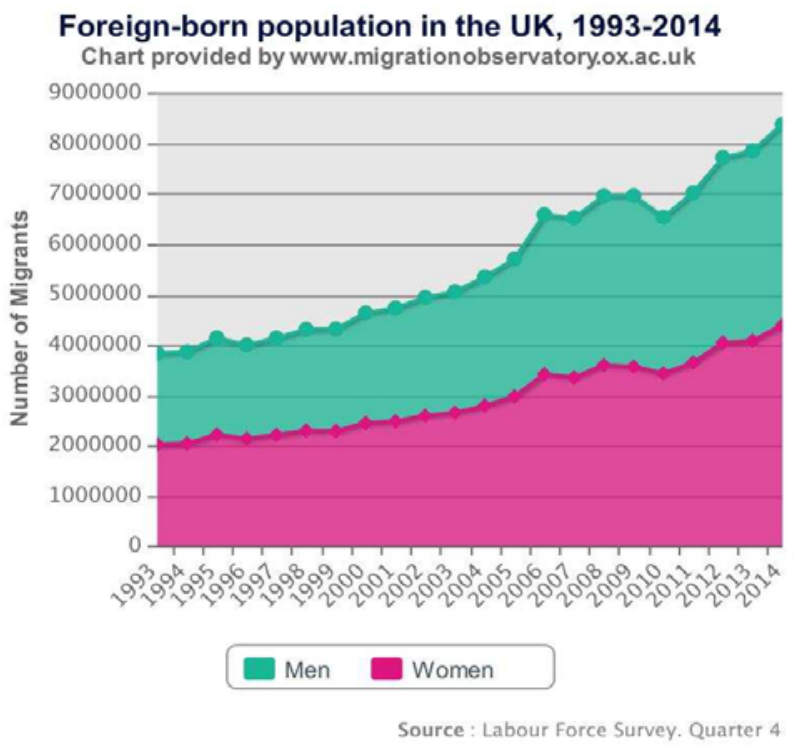

Fig. 1. The migrants population changes chart.

During the same period the number of foreign citizens increased from nearly 2 million to more than 5 million. The number of foreign-born people in the UK increased almost every year, although there were slight decreases in 1996, 2007 and 2010, while the number of foreignborn has increased again since 2011 (fourth quarter data). Over the whole time period analysed (1993 to 2014) the highest growth in the foreign-born population occurred between 2005 and 2008. This period coincides with the significant inflow of East European migrants following EU enlargement in 2004.

"The same Migrants in the UK: An Overview", published in 2015, says that for 2013 India, Poland, and Pakistan are the top three countries of birth for the foreign-born (Table 1) accounting respectively for 9.2, 9.1 and $6.0 \%$ of the total, followed by Ireland and Germany. India and Poland remain the top two countries of citizenship of foreign citizens, with Poles being the biggest group, accounting for about $15 \%$ of the total.

Although there is no official data on the current (January, 2016) changes of the outcoming countries, the study of the factual material shows that the list has actually changed, and now includes refugees from the Middle East territories involved in the current conflicts.

Table 1. Top ten sender countries of migrants by country of birth and nationality, UK 2013

\begin{tabular}{|l|l|l|l|}
\hline $\begin{array}{l}\text { Country of } \\
\text { birth }\end{array}$ & $\begin{array}{l}\text { Percentage } \\
\text { share }\end{array}$ & $\begin{array}{l}\text { Country of } \\
\text { citizenship }\end{array}$ & $\begin{array}{l}\text { Percentage } \\
\text { share }\end{array}$ \\
\hline India & 9.2 & Poland & 15.1 \\
\hline Poland & 9.1 & India & 7.3 \\
\hline
\end{tabular}

\begin{tabular}{|l|l|l|l|}
\hline $\begin{array}{l}\text { Country of } \\
\text { birth }\end{array}$ & $\begin{array}{l}\text { Percentage } \\
\text { share }\end{array}$ & $\begin{array}{l}\text { Country of } \\
\text { citizenship }\end{array}$ & $\begin{array}{l}\text { Percentage } \\
\text { share }\end{array}$ \\
\hline Pakistan & 6.0 & Ireland & 6.2 \\
\hline Ireland & 4.4 & Italy & 3.6 \\
\hline Germany & 3.6 & Pakistan & 3.6 \\
\hline South Africa & 2.5 & Romania & 3.5 \\
\hline Nigeria & 2.4 & Lithuania & 3.3 \\
\hline Bangladesh & 2.4 & Portugal & 3.2 \\
\hline Romania & 2.2 & France & 3.0 \\
\hline $\begin{array}{l}\text { United } \\
\text { States }\end{array}$ & 2.0 & Germany & 2.7 \\
\cline { 1 - 3 } & & &
\end{tabular}

Thus, the scale of the European power, according to media reports, is unable to fully host the entire Islamic world. However, the case makes the life of native people really complicated and they are not ready to react properly, they form a negative attitude of society, which is not quite in line with what, by definition, is called tolerance. The response of the Islamic world to such an attitude is often associated with terrorism. The latter changes the mood of Europeans further and cultivates their negative attitude. Irreversible changes occur in society, the traditional way of life of Europeans undergoes transformation, the language changes. And not only that immigrants bring new lexemes, customs and traditions, language captures everything that happens in society at a particular historical moment. This way, the language changes especially in the current period are the significant. English is undergoing a kind of "attack" of the coming languages, but in the process of survival of both languages they are trying to assert their own independence. In connection with the above mentioned, the relevance of project undertaken, which is aimed at a comprehensive description of the problem of linguistic identity in the linguistic culture in terms of contemporary socio-political situation in the world is very high. In addition, a relevant scientific result in the form of a database of lexical units collected in the synchronous language cut in the two countries will become a verbal monument to events and a material for comparison with identical material in synchrony. Of no less importance is the development and creation an educational and informational resource aimed not only at teaching students some aspects of intercultural communication, their tolerant attitude to what is happening. The research innovation lies in a complex linguistic and non-linguistic use of methods, the development of the language-level model of invariants and variants influenced by interethnic and interfaith contacts, allowing fixing the language changes and anticipate them, creation of a computer program to monitor the language situation in the regions.

The current socio-political situation in the world and the state of inter-cultural and inter-religious relations in general, and in the UK in particular, can not be characterized uniquely. Policy tolerance and multiculturalism, previously erected by the West to the 
rank of priority, tolerates present debacle, and this has long been officially recognized by the British authorities in the media (see, for example: Cameron David PM's speech at Munich Security Conference // The official site of. . the British Prime Minister's Office - URL: http://www.number10.gov.uk/news/pms-speech-at-

munich-security-conference/). In this model multiculturalism and universal tolerance to a large ethnic and religious communities that are poorly adapted to the Western cultural canon and are not able to fully integrate into the British community, are replaced by the new farright sentiment that "resist" Islam, oppose the Muslim communities in the country. It is justifies by the fact that the latter are other carriers that are incompatible with Western, cultural norms and traditions that are a threat to the normal existence and development of the British nation. Western democracy, freedom of expression of the media allow authoritative authentic British publications such as The Times, Daily Telegraph, The Independent, etc. Broadcast Corporation BBC provide updated information regarding the objective of the political attitudes of higher echelons of power of Great Britain to influence public attitudes and to form general negative attitude of the British to the active flow of refugees; such media can be considered primarily informational. This emotional period of $1990-2015$ is possible to characterize with the materials based on video sharing You Tube, social networks, blogs and websites of official and unofficial organizations confronting Islam. Developing on the basis of the mass of zombies in the discursive space of the media and Internet resources, the antiterrorist and neo-fascist sentiment was particularly quickly picked up by young people and, of course, have a verbal expression (and, unfortunately, not only verbal) in the pages of the virtual space. This situation is understandable, because the modern world, taking into account the mobility of the mood of society and the political situation, which raises the urgent question of identity of the younger generation in their attempt to understand and define their place among their peers and the older generation, to find their lingvocultural identity. And if the earlier native English youth who lived in the era of the tolerance, "coexisted" with Islam, adapted and took over some of the traditions of the Muslim world (for example, young men grow beards, dressed, resembling the Muslim men, called the new fashionable trend "Arabian Chic"), now the Public Internet, social networks and hosting are full of sharp negative attitude to the Islamic world. They tend to selfidentification, not only through membership in antiIslamic Internet companies, but also by the statements of sharply negative attitude to the policy of tolerance in the form of comments in blogs. Indeed, in the minds of British youth, grown in a conservative high society, the priority has always been and will be its national identity, while the Islamic world will always be profiling its religious basis. John Russell, a professor at the University of Bradford, claims: "United Kingdom - a secular society. If you ask the average Englishman, he would say that he is a Catholic, a Protestant, a Jew; he would answer - British Muslims or Englishman - in a different way, "see: http://www.bbc.com/russian/multimedia/ 2015/07 150720_5floor_pm_strategy_against_is). Such a difficult political and social aspect of the situation in the UK and the attitude to it, mainly among the youth as the most vulnerable to the influence of the media and the Internet, has a verbal expression in the form of the estimated vocabulary of new words quickly entering into the everyday life and change the value of the already known words considering modification factor values and the emergence of secondary nomination.

Therefore, the study of web-resources with relevant tags shows the great popularity of the theme. Thus, for example, Tony Blair: Do not blame migrants for taking your job (http://www.telegraph.co.uk/news/politics/tonyblair/12

192682/Tony-Blair-Dont-blame-migrants-for-takingyour-job.html); Secret report warns of migration meltdown in Britain (http://www.dailymail.co.uk/news/ article-398232/Secret-report-warns-migration-meltdownBritain.html); Angela Merkel's historic error on immigration (http://www.telegraph.co.uk/news/worldne ws/europe/germany/angela-merkel/12193876/AngelaMerkels-historic-error-on-immigration.html); Migrants to take HALF of all new homes in Britain....and it could cost taxpayers MILLIONS (http://www.express.co.uk/news/uk/624279/UK-immigra tion-migrants-homes-Britain-help-to-buy); Justin Welby is right: It's not racist to worry about the migrant effect (http://www.telegraph.co.uk/news/uknews/immigration/ 12191532/Justin-Welby-is-right-Its-not-racist-to-worryabout-the-migrant-effect.html); Justice minister: David Cameron can only deliver promise to cut migration by leaving

$\mathrm{EU}$ (http://www.telegraph.co.uk/news/uknews/immigration/ 12191594/Justice-minister-David-Cameron-can-onlydeliver-promise-to-cut-migration-by-leaving-theEU.html); Ministers accused of hiding true scale of migration and real number may not emerge until the eve of referendum

(http://www.telegraph.co.uk/news/uknews/ immigration/12191579/True-scale-of-EU-migrationcould-emerge-on-eve-of-referendum.html).

We see mass media are filled with the different aspects of the immigration problem. The most popular is the aspect concerning the costs of British immigration policy, then comes the questions of antiterrorist security and employment. Mostly, the mood music on the studied materials present concerned, even panic mood. Even the religion is in the theme, trying to eliminate that panic attitudes. This becomes a part of a new sociological phenomenon - "moral panic".

Moral panics arise when distorted mass media campaigns are used to create fear, reinforce stereotypes and exacerbate pre-existing divisions in the world, often based on race, ethnicity and social class

The moral panic concept has been applied to a wide range of social problems including but not limited to youth gangs, flag burning, illegal immigration and terrorism. Central to the moral panic concept is an argument that public concern or fear over an alleged social problem is mutually beneficial to state officials. That is, it is beneficial for politicians, law enforcement 
authorities and the news media. The relationship between state officials and the media is symbiotic; in that politicians and law enforcement needs communication channels to distribute their rhetoric and the media need tantalizing news content to attract a wide audience, which, in turn, attracts advertisers.

Additionally, moral panics have three distinguishing characteristics. First, there is a focused attention on the behavior, whether real or imagined, of certain individuals or groups that are transformed into what Cohen referred to as "folk devils" by the mass media. This is accomplished when the media strip these folk devils of all favorable characteristics and apply exclusively negative ones. Second, there is a gap between the concern over a condition and the objective threat it poses. Typically, the objective threat is far less than popularly perceived due to how it is presented by authorities. Third, there is a great deal of fluctuation over time in the level of concern over a condition. The typical pattern begins with the discovery of the threat, followed by a rapid rise and then peak in public concern, which then subsequently, and often abruptly, subsides. Finally, public hysteria over a perceived problem often results in the passing of legislation that is highly punitive, unnecessary, and serves to justify the agendas of those in positions of power and authority.

Moral panic is both a public and political response to an exaggeration or distortion of the threat posed to society by some allegedly harmful individual or group. More specifically, moral panic includes an exaggeration of certain events by enhancing the empirical criteria such as the number of individuals involved, the level and extent of violence, and the amount of damage caused. Thus, it is more than obvious, that society, transmitting corcern and panic, can not function stable, that inevitably leads to social disorders.

\section{Conclusion}

In the modern socio-political situation the scale of the European power, according to media reports, is unable to fully host the entire Islamic world. However, the case makes the life of native people really complicated and they are not ready to react properly, they form a negative attitude of society, which is not quite in line with what, by definition, is called tolerance. The response of the Islamic world to such an attitude is often associated with terrorism. The latter changes the mood of Europeans further and cultivates their negative attitude. Irreversible changes occur in society. The traditional way of life of Europeans undergoes transformation, the language changes. And not only that immigrants bring new lexemes, customs and traditions, language captures everything that happens in society at a particular historical moment. This way, the language changes especially in the current time are significant. English is undergoing a kind of "attack" of the coming languages, but in the process of survival of both languages they are trying to assert their own independence. In connection with the above mentioned, the relevance of project undertaken, which is aimed at a comprehensive description of the problem of linguistic identity in the linguistic culture in terms of contemporary sociopolitical situation in the world is very high. A language is a powerful knowledge of battery found to store, process and transmit the knowledge in verbal expression from generation to generation, as well as to capture the historical era, the attitude towards them in the diachronic aspect in all historical periods, at the moment, taking into account existing in the arsenal of the linguist of the modern and traditional tools, extra-linguistic knowledge and the possibility of their involvement in order to achieve the objectivity of the study. It is possible to describe the specifics of English "new politicized" generation of British youth, responding to acute political situation in the country and Europe, which gives its own answer to the failed policy of multiculturalism and, more than any other age group of British, tends to selfidentification. This trend towards a kind of return to British values, opposition to the absorption of the Islamic world of traditional conservative values and the English language of the nation currently represent one of the most relevant topics for the development of not only historic, but also linguistical. I think that the description of British youth language in the virtual space as the most accessible, in terms of free expression of emotional state of young people, who regularly attend the resource, significantly complement the active historical development and form an idea of the state of the EU citizens in an era of such significant change and crisis. In addition, it will organize appropriate nominative units, review and refine their values change, predict the axiological shades of semantics that can reflect the identity among the youth, record and organize occasionalisms and neologisms. The need for monitoring and recording, which takes place in an era of such significant political and social plans for change is evident not only and not so much for determining of the attitudes of British youth, but how to describe the evolutionary semantics movement, it changes to the synergy of language development in the syncretism of the culture and changes in a person. In addition, the solution of the problem description and the fastest "clearly" variable in the vast virtual space of a formation of the youth lexicon will complement the knowledge of a language as a synergetic self-organizing system that can adapt to the demands of the external non-linguistic (social, political, economic) factors.

\section{References}

1. The Migration Observatory At The Oxford University, "Migrants in the UK: an Overview" (2015)

2. Scott A., Bonn Ph.D., Moral Panic: Who Benefits From Public Fear? (2015)

3. V.B. Kashkin, Introduction to the Theory of Communication (VSTU Editorial, 2000)

4. D. Altheide, 'Moral Panic : From Sociological Concept to Public Discourse' (Crime, Media and Culture, vol 5:1, 2009) 
5. N.F. Alefirenko, Lingvoculturology. Evaluativemeaningful laguage sphere (Flinta, 2010) 